\title{
The plasma membrane in cardiomyopathy
}

\author{
WiNIFRED G. NAYLER \\ D.Sc.
}

W. BURIAN
M.D.

The Cardiothoracic Institute, 2 Beaumont Street, London W1N 2DX

\section{Summary}

A drug-induced change in the fine morphology of the plasma membrane of heart muscle cells is described. Thus, in rabbits the chronic administration of oxyfedrine caused a marked proliferation of the plasma membrane. At the same time the mitochondria became swollen and vacuolated, and there was evidence of lysis of myofibrils. These changes are not accounted for in terms of the release of endogenous stores of catecholamines.

These investigations were supported by grants in aid from the British Heart Foundation and the National Medical Research Council of Great Britain.
THE plasma membrane forms an integral part of the sarcolemmal complex. This complex can easily be differentiated into three components-a diffuse reticulum of collagen fibrils, an extracellular protein-polysaccharide coating and the plasma membrane. From a functional point of view it is relatively easy to distinguish the plasma membrane from its extraneous coat because, as discussed in detail by Stoeckenius and Engleman (1969), it is the plasma membrane and not the basement coat which provides the main permeability barrier, and which contains the firmly bound multienzyme complexes. Moreover, whereas the protein-polysaccharide coating and the associated collagen fibres of the basement

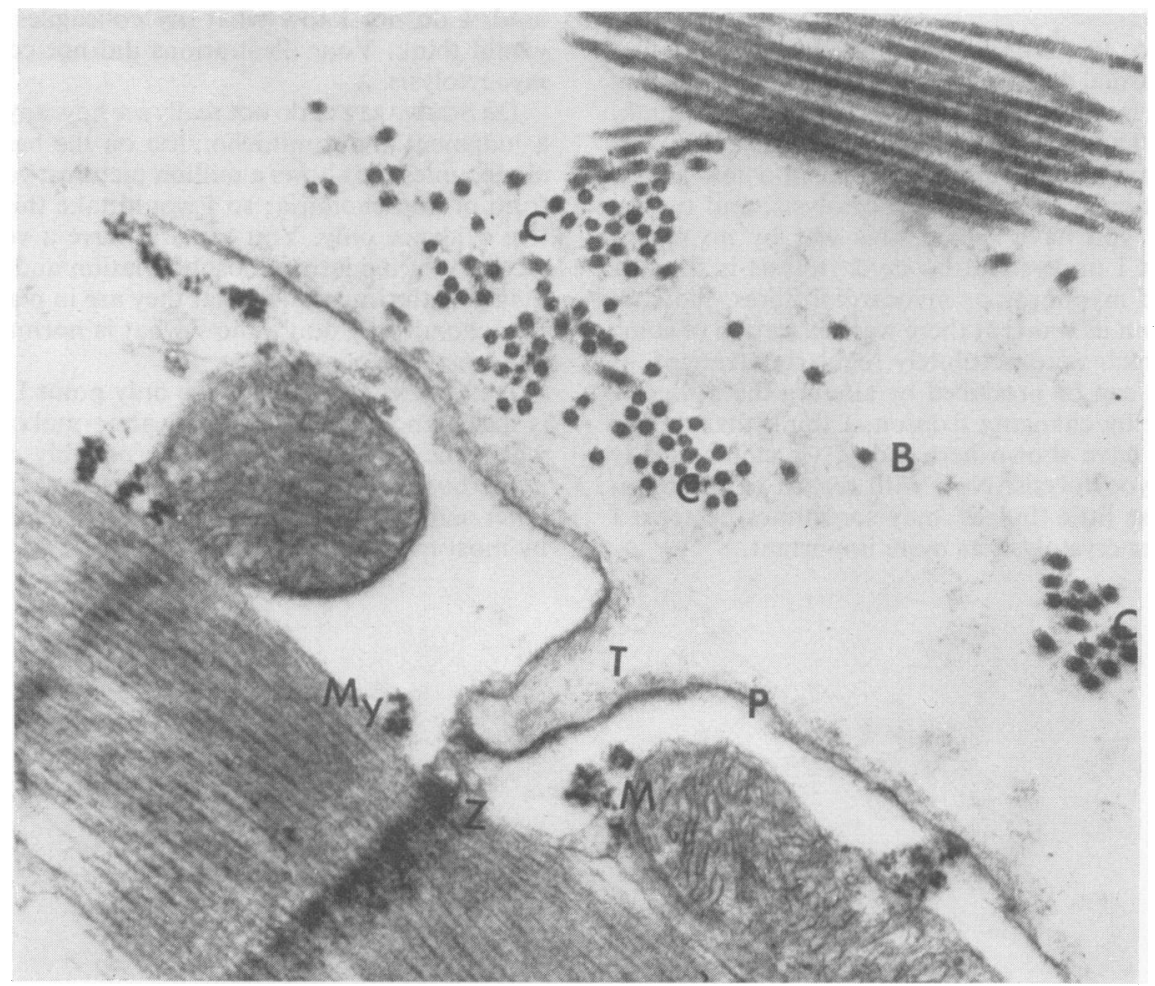

FIG. 1. Longitudinal section through the sarcolemmal complex of a rabbit ventricular muscle cell $(\times 64,000)$. Note the presence of $(C)$, collagen fibrils, the thick basement coat (B), and the plasma membrane (P). The plasma membrane indents to form a $\mathrm{T}$-tubule at the level of the $\mathrm{Z}$ band. $\mathrm{M}$ denotes mitochondria and $\mathrm{My}$ the myofibrils. 
coat can be stripped from the remainder of the cell membrane without seriously impairing the viability of the cell, damage to the plasma membrane invariabty impairs the functioning of the cell.

Although the protein-polysaccharide layer of the basement coat provides a relatively thick protective layer for the plasma membrane (Fig. 1) the plasma membrane itself is relatively thin, e.g. it is only $90 \AA$ wide in cat and $80 \AA$ in sheep ventricular muscle cells (Fawcett and McNutt, 1969; Simpson and Oertelis, 1962). Of course the plasma membrane of some muscle cells is significantly thinner than this, e.g. in the walking leg muscle of the crayfish the plasma membrane is only $60 \AA$ wide (Brandt et al., 1965).

\section{The distribution of the plasma membrane in heart muscle cells}

In a wide variety of cardiac muscle cells the distribution of the plasma membrane is exceedingly complex. Thus, whereas in the ventricular muscle cells of a few species of animals, including the domestic chicken, lizards, and toads (Nayler and Merrillees, 1964) the plasma membrane appears to be relatively simple in its distribution and devoid of intracellular ramifications, in other animals, including rabbits, rats, dogs, guinea-pigs, etc., regularly spaced tubular invaginations extend from the sarcolemma into the cytoplasm. Such a tubular invagination is shown in Fig. 1. By using electron-dense markers, e.g. colloidal lanthanum, horseradish peroxidase and ferritin (Huxley, 1964; Forssmann and Girardier, 1970; Nayler and Merrillees, 1971) it has been relatively easy to show that the lumen of these tubular invaginations of the plasma membrane are continuous with the extracellular space (Simpson and Oertelis, 1962; Fawcett and McNutt, 1969). These inwardly directed tubular extensions are lined with a membrane which is approximately $90 \AA$ wide, and which is continuous with and indeed part of the plasma membrane (Peachey, 1965). Another example of such a tubular invagination is shown in the electronmicrograph reproduced in Fig. 2.

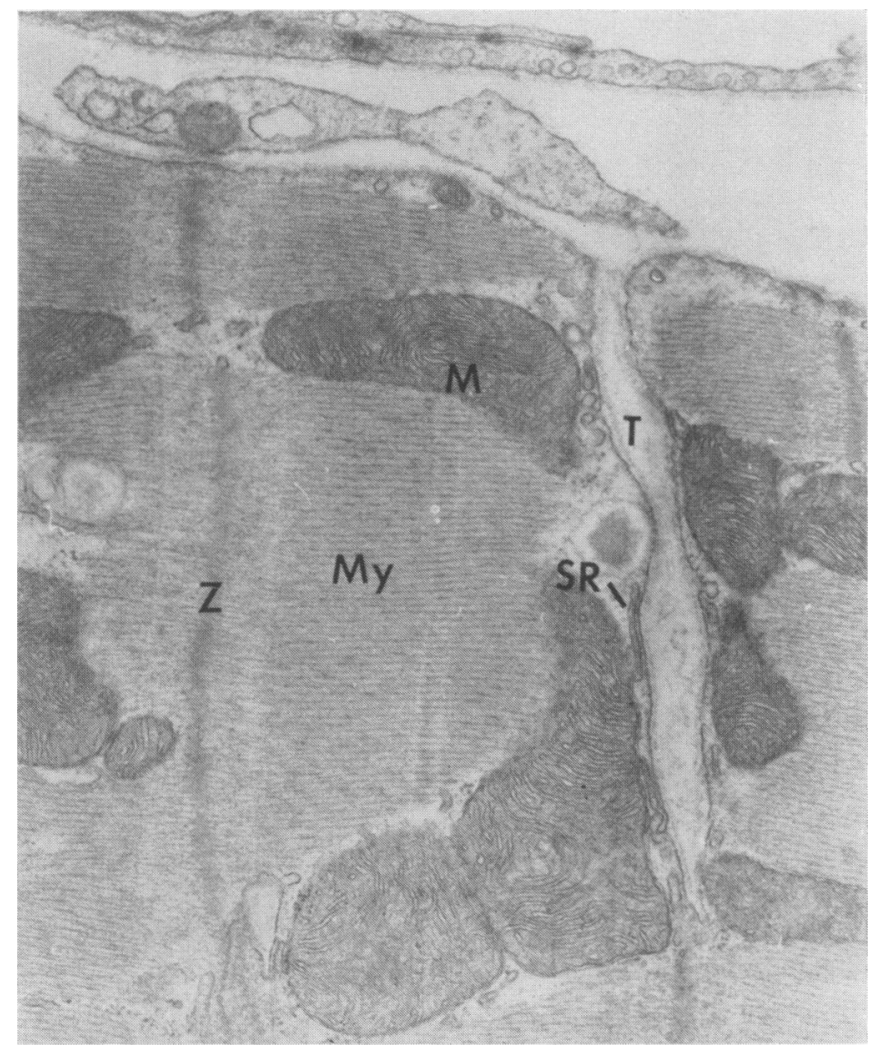

FIG. 2. Longitudinal section across part of a ventricular muscle cell from rabbit heart muscle $(\times 30,000)$. Note evidence of pinocytotic activity along the T-tubule. $Z$, $\mathrm{M}, \mathrm{My}, \mathrm{T}$ as in Fig. 1. S.R. denotes elements of the sarcoplasmic reticulum. 
There are, of course, several aspects of such a tubular invagination which warrant attention. (a) It is located at the level of the $Z$ band; (b) it closely approximates the mitochondria; (c) it displays pinocytotic activity; (d) it is separated from the profiles of the sarcoplasmic reticulum by a distance of only approximately $200 \AA$; (e) it is lined by plasma membrane and basement coat; (f) it extends deep into the muscle cell.

Although the existence of these T-tubular ramifications of the plasma membrane has been recognized for many years (Porter and Palade, 1957) it is only recently that we have become aware of the fact that their appearance and distribution is altered following the chronic administration of certain drugs. Thus, for example in rabbits the administration of the drug oxyfedrine (1- $w$-[ $\beta$-hydroxy- $\alpha$-methylphenylamino]3-methoxypropriophenone-HCl, Ildamen, R., CibaGeigy Ltd, England) in relatively large (5-15 $\mathrm{mg} / \mathrm{kg}$ ) doses, causes a marked proliferation and branching of these T-tubular profiles, as shown in the electronmicrographs reproduced in Figs 3, 4, and 5. These electronmicrographs show that in rabbits which have been pretreated with the drug oxyfedrine, long villi-like projections extend down from the cell membrane (Figs 4 and 5). These villi-like projections are filled with dense basement coat substance and they come into close proximity to the mitochondria. The appearance of these villi-like extensions cannot readily be accounted for in terms of diet because, although the oxyfedrine-treated animals did lose weight, their food intake was not restricted, and their heart weight to body weight ratio remained normal. Likewise, depletion of the endogenous stores of catecholamines cannot be said to cause the growth of these villi-like projections, because oxyfedrine does not deplete the cardiac stores of catecholamines in the rabbit as it does in the rat (Appel et al., 1973).

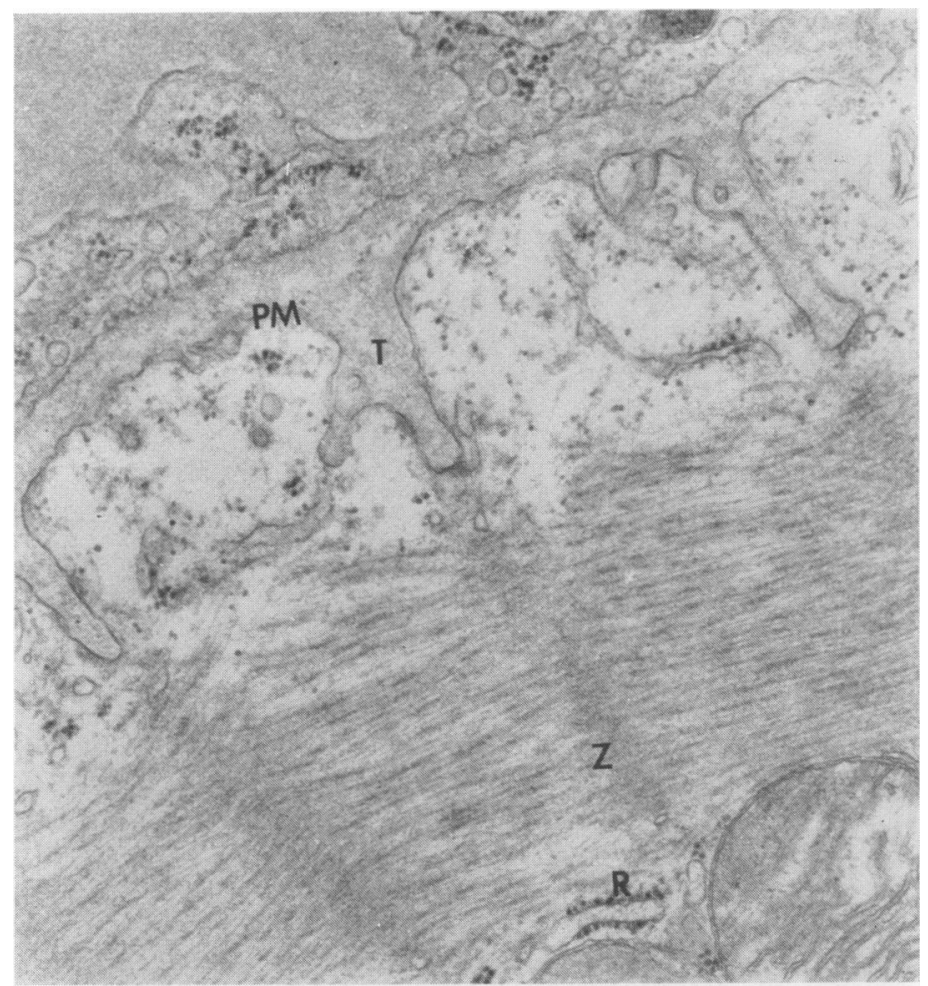

FIG. 3. Longitudinal section through a rabbit papillary muscle cell, showing extensive branching of the plasma membrane (P.M.) $(\times 48,000)$. Note that the myofilaments (My) have a wispy appearance compared to those shown in Fig. 2, and the $Z$ bands are thickened. $R$ denotes ribosomes. This rabbit had been given oxyfedrine, $15 \mathrm{mg} / \mathrm{kg}$, i.p. for 6 weeks. 
Oxyfedrine evoked other changes in the fine morphology of heart muscle cells, e.g. the mitochondria were often swollen and vacuolated, the myofibrils were often disorganized and showing signs of lysis, and there was a proliferation of ribosomal activity.

The functional significance of such a drug-induced change in the distribution of the plasma membrane may be relatively important, because of the implied change in the cell volume to surface area ratio and the attendant changes in the diffusion characteristics of the plasma membrane relative to the cell. One wonders whether or not these altered diffusion characteristics could be involved in the beneficial use of such drugs in the relief of angina pectoris. It must be emphasized, however, that these studies were performed in rabbits and it is possible that the response is species specific.

The functional significance of this drug-induced change in the distribution of the plasma membrane may be most easily understood if it is discussed in terms of the ionic events involved in the processes associated with excitation-contraction coupling, because it is the ability of the plasma membrane to alter its selective ionic permeability which determines whether the intracellular ionic milieu is such that excitation-contraction coupling can take place.

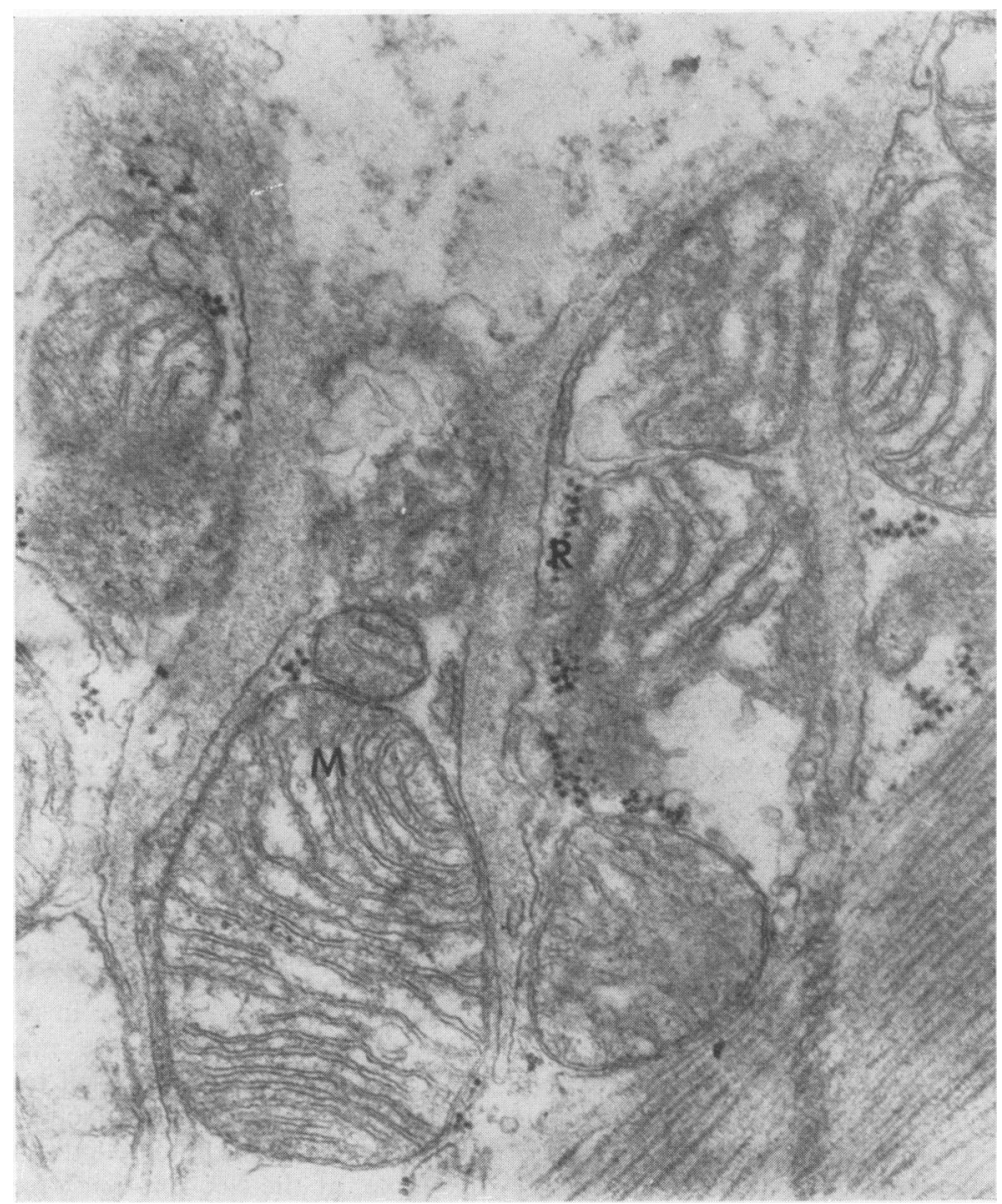

FIg. 4. Long villi-like profiles extending down from the sarcolemmal complex into the muscle cell. Note disorganization of the mitochondria ( $\times 100,000)$. Rabbit papillary muscle cell from rabbit treated with oxyfedrine $15 \mathrm{mg} / \mathrm{kg}$ daily, 6 weeks. Note presence of ribosomes (R) and partially lysed myofilaments. 


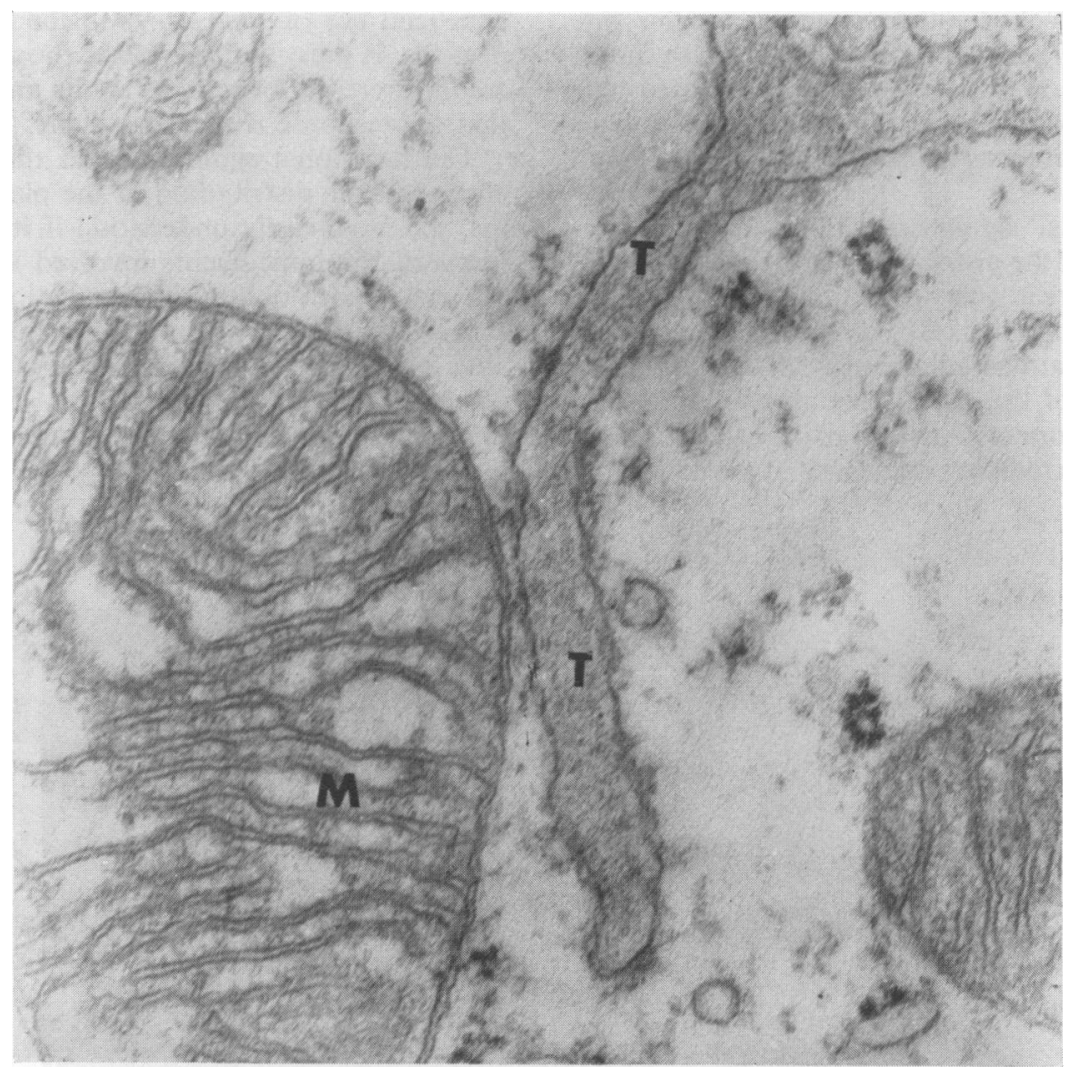

Fig. 5. Part of a rabbit papillary muscle cell from rabbit pretreated with oxyfedrine, $15 \mathrm{mg} / \mathrm{kg}$ daily, 3 weeks. Note long tubular profile $(\mathrm{T})$ extending from the sarcolemma and coming close to the mitochondrion $(\mathrm{M})(\times 100,000)$.

The functional significance of the plasma membrane in the series of events associated with excitationcontraction coupling.

There is convincing evidence from isotope and other studies to support the hypothesis that the activation of contraction in heart muscle cells depends upon an influx of $\mathrm{Ca}^{2+}$ from the extracellular phase. In normal heart muscle, however, as little as $1 \mathrm{nmol}$ of $\mathrm{Ca}^{2+}$ per gram of heart muscle is displaced inwards during the process of activation, shown schematically in Fig. 6. Since as much as $60-70 \mathrm{nmol}$ of $\mathrm{Ca}^{2+}$ per gram wet weight of heart muscle are needed to activate fully the contractile process additional $\mathrm{Ca}^{2+}$ must be released from other intracellular sources. The $\mathrm{Ca}^{2+}$ which enters the cell during the rising and plateau phases of the action potential (Nayler and Merrillees, 1971) accordingly may be regarded as 'trigger $\mathrm{Ca}^{2+}$ ', which in turn evokes the release of 'activator $\mathrm{Ca}^{2+}$ ' from intracellular storage sites. Biochemical studies have consistently shown that the sarcoplasmic reticulum of striated muscle cells (Katz and Repke, 1973; Schwartz, 1971) is capable of accumulating relatively large concentrations of $\mathrm{Ca}^{2+}$ and it seems probable that much of the $\mathrm{Ca}^{2+}$ which is needed to activate the interaction between actin and myosin originates from such sites. Possibly the scheme of events is similar to that shown in Fig. 7.

Such a scheme raises many questions, however. For example, how is the $\mathrm{Ca}^{2+}$-induced displacement of 'activator $\mathrm{Ca}^{2+}$ ' controlled? What role does the adenyl cyclase enzyme play in regulating the semipermeability of the plasma membrane to $\mathrm{Ca}^{2+}$ ? Is the excitatory stimulus itself transmitted from the plasma membrane to the facing membrane of the adjacent sarcoplasmic reticulum profile (as, for example, by the electron-dense feet which are found in the junctional gap in between the facing membranes of the sarcoplasmic reticulum and the plasma membrane (Franzini-Armstrong, 1972)? Is there any significance in the apparent constancy of the width of the junction gap? Obviously there are 


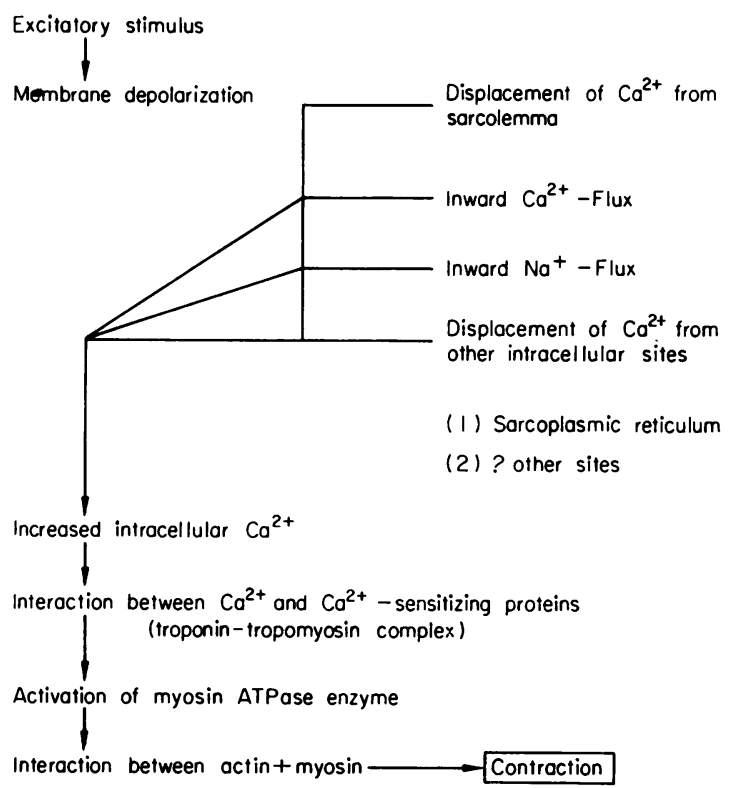

FIG. 6. Schematic representation of the series of events associated with excitation-contraction coupling in heart muscle cells.

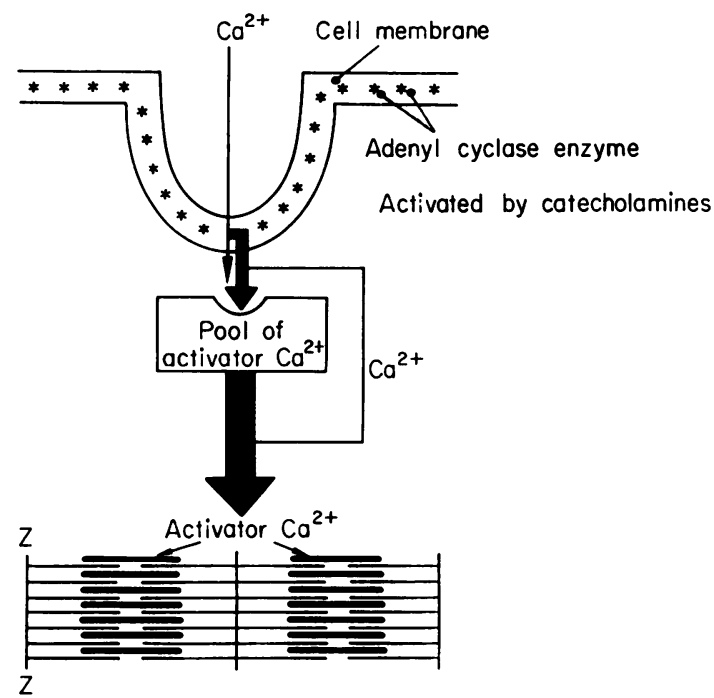

FIG. 7. Schematic representation of the role of trigger $\mathrm{Ca}^{2+}$ in releasing $\mathrm{Ca}^{2+}$ from an intracellular pool of 'activator $\mathrm{Ca}^{2+}$ '.

many questions to be answered concerning the spatial orientation and fine morphology of the structures involved in the process of excitation-contraction coupling, and it is logical to ask whether or not changes in the fine morphology of the plasma membrane such as those which have been presented here will modify the series of events (Figs 6 and 7) which are involved in excitation-contraction coupling.

Increasing the intracellular concentration of $\mathrm{Ca}^{2+}$ above the critical level of $10^{-7} \mathrm{M}$ provides only the first step in the series of events which results in the onset of the mechanical response. Thus, by interacting with the regulatory proteins (troponin and tropomyosin), $\mathrm{Ca}^{2+}$ reverses the inhibitory effect which they exert on the actin-induced activation of the myosin ATPase enzyme. If this actin-induced activation of the myosin ATPase enzyme is allowed to proceed, then ATP will be hydrolysed at a rate which is sufficiently fast to provide the high energy phosphate bonds needed for activating the cross bridges between the actin and myosin filaments, and hence for activating the contractile process.

Because the initiation of contraction depends upon the entry of $\mathrm{Ca}^{2+}$ across the plasma membrane from the extra to the intracellular phase the functional significance of the role played by the plasma membrane in the normal functioning of heart muscle cells cannot be over emphasized. It is pertinent to ask, therefore, whether other drugs alter the fine morphology of this enzymatically-active, structurally-complex plasma membrane, and if other drug-induced changes do occur will they be recognized as such at biopsy?

\section{References}

Appel, E., Planz, G., Schmid, B., Palm, D. \& Grobecker, H. (1973) Noradrenaline depleting effect and metabolism of oxyfedrine in rats. Naunyn-Schmiedeberg's Archives of Pharmacology, 280, 373.

Brandt, P.W., Reuben, J.P., Girardier, L. \& Grundfest, H. (1965) Correlated morphological and physiological studies on isolated single muscle fibers. 1 . Fine structure of the crayfish muscle fiber. Journal of Cell Biology, 25, 233.

FAWCETT, D.W. \& MCNutT, N.S. (1969) The ultrastructure of the cat myocardium. I. Ventricular papillary muscle. Journal of Cell Biology, 42, 1.

ForssmanN, W.G. \& Girardier, L. (1970) A study of the T-system in the rat heart. Journal of Cell Biology, 44, 1.

Franzini-Armstrong, C. (1972) Studies of the triad. 3. Structure of the junction in fast twitch fibres. Tissue and Cell, 4, 469.

HuXLEY, H.E. (1964) Structural evidence concerning the mechanism of contraction in striated muscle. In: Muscle (Ed. by W. M. Paul, E. E. Daniel, C. M. Kay and G. Monckton), Proceedings of the Symposium held at the Faculty of Medicine, University of Alberta. Pergamon Press, Oxford.

KATZ, A.M. \& REPKE, D.I. (1973) Calcium-membrane interactions in the myocardium: effects of ouabain, epinephrine and $3^{1}, 5^{1}$-cyclic adenosine monophosphate. American Journal of Cardiology, 31, 193.

NAYler, W.G. \& Merrillees, N.C.R. (1964) Some observations on the fine structure and metabolic activity of normal and glycerinated ventricular muscle of toad. Journal of Cell Biology, 22, 533. 
Nayler, W.G. \& Merrillees, N.C.R. (1971) Cellular exchange of calcium. In: Calcium and the Heart (Ed. by P. Harris and L. H. Opie), p. 24. Academic Press.

Peachey, L.D. (1965) The sarcoplasmic reticulum and transverse tubules of the frog's sartorius. Journal of Cell Biology, 25 (Suppl.), 209.

Porter, K. R. \& Palade, G.E. (1957) Studies on the endoplasmic reticulum. III. Its form and distribution in striated muscle cells. Journal of Biophysical and Biochemical Cytology, 3, 269-299.
Schwartz, A. (1971) Calcium and the sarcoplasmic reticulum. In: Calcium and the Heart (Ed. by P. Harris and L. H. Opie), p. 66. Academic Press.

Simpson, F.O. \& Oertelis, S.J. (1962) The fine structure of sheep myocardial cells; sarcolemmal invaginations and the transverse tubular system. Journal of Cell Biology, 12, 91.

Stoeckenius, W. \& Engleman, D.M. (1969) Current models for the structure of biological membranes. Journal of Cell Biology, 42, 613.

\section{Discussion}

Chairman: Thank you very much Dr Nayler. Your paper is now open for discussion.

DR RONA: You mentioned that the basement membrane is primarily affected.

DR NAYLER: Yes, that is true; but of course the myofibrils are also damaged.

DR RonA: And this will obviously alter sarcolemmal permeability also?

DR NAYLER: Well, I don't know, because we haven't looked yet. One assumes so.

DR RONA: Yes, there is some clearing of sarcoplasm in these cells. This method offers a very neat demonstration of sarcolemmal permeability.

DR NAYLER: These are only preliminary findings.

DR BRACHFELD: Have you studied other tissues as well?

DR NAYLER: No; so far we have concentrated on the changes in heart muscle.
Chairman: Have you looked at any other drugs? $\beta$-globulins or $\beta$-stimulants?

DR NAYLER: We are currently looking at the effect of long term treatment with $\beta$-antagonists.

Dr ScHwartz: Any biochemical changes that you can mention at this point?

DR NAYLER: The sarcoplasmic reticulum shows no change in its calcium accumulating activity. The plasma membrane shows a decreased ATPase activity.

DR CARlisle: Were the doses of drugs comparable to those you would have used clinically?

DR NAYLER: We have gone right through the whole dose range and one can see graded series of changes. Doses comparable with those used clinically certainly produced marked changes at the level of the cell membrane. 